\title{
SNOW-SLAB STUDIES AT WHISTLER MOUNTAIN, BRITISH COLUMBIA, GANADA
}

\author{
By C. STethem \\ (Garibaldi Lifts Ltd, Whistler, British Columbia VoN ıBo, Canada) \\ and R. PERLA \\ (Environment Canada, Canmore, Alberta ToL oMo, Canada)
}

\begin{abstract}
Aвstract. A study of 30 slab avalanches at Whistler Mountain ski area, British Columbia, indicates that slab instability initiates with highest frequency on $40^{\circ}$ slopes, that the temperature at the slab bed surface is about $-5^{\circ} \mathrm{C}$ averaged for the 30 cases, and that on the average the slabs have a snow density of about $220 \mathrm{~kg} / \mathrm{m}^{3}$. These results agree well with results from earlier studies. A rich variety of crystals appear in photomicrographs of samples extracted from the bed surfaces of the 30 slabs. In many cases, crystals extracted from the plane of critical weakness do not differ markedly from crystals extracted from adjacent strata.
\end{abstract}

RÉsumé. Études de plaques de neige à Whistler Mountain, Colombie-Britannique, Canada. Une étude de 30 avalanches de plaques à la station de ski de Whistler Mountain en Colombie-Brittanique, montre que l'instabilité des plaques de neige apparaît le plus fréquemment sur les pentes inclinées à $40^{\circ}$, que la température de la surface de glissement de la plaque est d'environ $-5^{\circ} \mathrm{C}$, selon une moyenne établie sur 30 cas; et que la densité moyenne de la neige de ces plaques est d'à peu près $220 \mathrm{~kg} / \mathrm{m}^{3}$. Ces résultats concordent bien avec des études antérieures. On voit apparaître une très grande variété de cristaux examinés par photomicrographie dans les échantillons extraits de la zone de glissement des 30 plaques. Dans beaucoup de cas, les cristaux extraits au niveau du plan de fragilité critique ne diffèrent pas énormément des cristaux extraits des couches adjacentes.

Zusammenfassung. Schneebrettstudien am Whistler Mountain, British Columbia, Kanada. Eine Untersuchung von 30 Schneebrettlawinen im Skigebiet am Whistler Mountain, British Columbia, zeigt, dass Schneebretter am häufigsten bei einer Hangneigung von $40^{\circ}$ instabil werden, dass die Temperatur an der Grundfläche der Bretter im Mittel der 30 Fälle etwa $-5^{\circ} \mathrm{C}$ beträgt und dass die Bretter eine mittlere Schneedichte von $220 \mathrm{~kg} / \mathrm{m}^{3}$ besitzen. Diese Ergebnisse stimmen gut mit denen früherer Untersuchungen überein. An Proben, die aus den Grundflächen der 30 Bretter entnommen wurden, lässt sich durch Photomikroskopie und aus Photomikrographien eine reiche Vielfalt von Kristallen feststellen. In vielen Fällen unterscheide sich Kristalle aus der Fläche kritischer Nachgiebigkeit nicht merklich von solchen aus benachbarten Schichten.

\section{INTRODUGTION}

After a slab avalanche releases, an effort is often made to reach the starting zone of the slab in order to inspect the snow in the vicinity of the slab fracture surfaces. This inspection usually reveals important clues which pertain not only to the specific avalanche under investigation, but also to possible widespread stability problems that may be expected as the avalanche season progresses. More fundamentally, many avalanche scientists believe that systematic and quantitative information from the starting zone will lead to an improved theory of avalanche forecasting.

Our earlier study (Perla, 1977) summarizes 205 fracture-zone investigations made in a wide variety of mountain ranges and corresponding climates. In this paper we present 30 additional investigations made in British Columbia at the Whistler Mountain ski area, one of Canada's largest ski areas, and the Canadian ski area with the most extensive avalanche control programme. Stethem and Hetherington (1978) describe the Whistler climatology, avalanche hazard, and avalanche control programme. Over $90 \%$ of the Whistler slab hazard is in response to heavy snow-fall and involves the most recent layers of snow. However, our 30 investigations are biased by a high proportion of slabs consisting of older, metamorphosed snow, essentially the deeper and more insidious slabs. The study is also biased exclusively towards dry slabs and does not include any of the numerous wet slabs that release late in the spring. 
We measured the same parameters that are summarized by Perla (1977), except that we omitted the time-consuming shear-frame measurements. We introduced a new technique for photomicrography of snow crystals extracted from layers that coincided with, as near as we could estimate, the layers of critical weakness at the slab's lower boundary.

\section{Terminology}

Figure I shows an idealized cross-section of the slab's crown region, that is, the region of the upper tensile fracture. The main sliding surface is a convenient reference plane which we call the bed surface. We envision this plane to extend beneath the crown, thus forming in our terminology a bed-surface extension. Ideally, the main shear weakness, which is a layer of finite thickness, also extends beneath the crown at a level immediately above the bed-surface extension. We call this weak layer the gleitschicht, preserving the German terminology

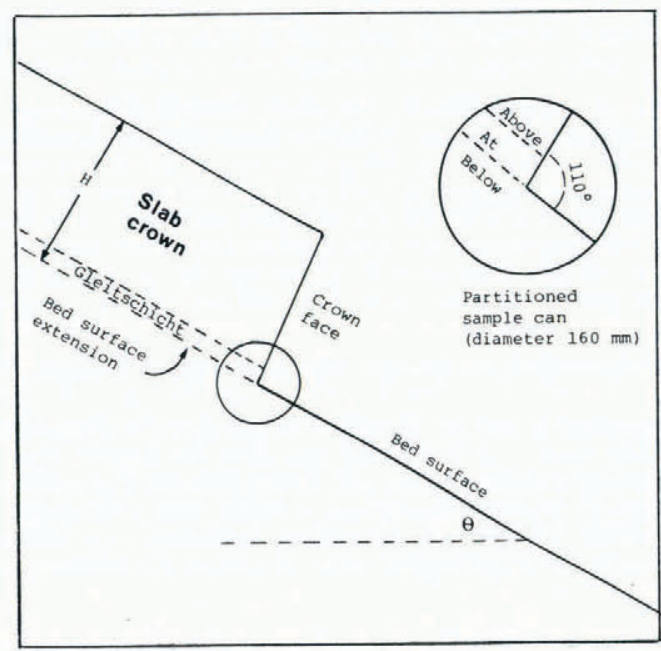

Fig. I. Idealization of crown region.

introduced in the Swiss avalanche literature. The idealization of Figure $\mathbf{I}$ is probably an oversimplification of nature. In many cases, the weak layer appears to have noticeable thickness below the bed-surface extension, and in some cases seems to include the entire substratum to the ground level.

The slab crown is characterized by a thickness $H$, and a mean density $\rho_{\mathrm{s}}$, averaged over the thickness $H$. The bed surface is characterized by its inclination $\theta$, measured immediately down-slope from the centre of the crown. The bed-surface extension is characterized by a temperature $T_{\mathrm{B}}$, and a density index $\rho_{\mathrm{B}}$. The latter is more precisely the density index of the layer that is immediately above the bed-surface extension. Presumably $\rho_{\mathrm{B}}$ is a reasonable density index of the gleitschicht, or at least the upper portion of the gleitschicht.

\section{Methods: SLAB MEASUREMENTS}

Investigations were made as soon as possible after avalanche release. For 22 of the 30 investigations, elapsed time from avalanche release to measurement was $5 \mathrm{~h}$ or less. The remaining 8 investigations were postponed until the day following the avalanche with elapsed times ranging from 12 to $28 \mathrm{~h}$. The index that loses meaning fastest with increasing elapsed 
time is $T_{\mathrm{B}}$. This measurement was not included in the study if the elapsed time exceeded $5 \mathrm{~h}$. $T_{\text {B }}$ was measured in a pit excavated at least $0.5 \mathrm{~m}$ up-slope from the crown face in order to sample a portion of the bed-surface extension that was relatively free from thermal disturbance.

Slab density $\rho_{\mathrm{s}}$ was measured by weighing cylindrical samples, diameter $0.18 \mathrm{~m}$ and height $0.4 \mathrm{~m}$, cut from the crown across the entire slab layer. This weighing was performed in situ.

The density index $\rho_{\mathrm{B}}$ of the layer above the bed surface extension was obtained by cutting out a rectangular sample $20 \mathrm{~mm}$ thick by $100 \mathrm{~mm}$ wide by $100 \mathrm{~mm}$ long. Three samples were cut out for each investigation. These were placed in plastic bags and transported to a sheltered location where they were weighed on a triple-beam balance and averaged. Because of inclement weather, this delicate measurement was taken for only 8 of the 30 investigations. It can be argued that the measurement of $\rho_{\mathrm{B}}$ should be made by cutting as thin a sample as possible, but we found in preliminary studies that sampling errors increased by about a factor of five (from $2 \%$ to $10 \%$ ) when the sample thickness was decreased from $20 \mathrm{~mm}$ to $10 \mathrm{~mm}$.

To complete our records, the avalanche event was sized as either small, medium, or large, depending on a rough, subjective estimate of the destructive capability of the event. A small avalanche is capable of injuring an unprotected human; a medium avalanche can destroy a wood-frame house or auto; a large avalanche has enough capacity to destroy a village or a forest.

\section{Results: SLAB MEASUREMENTS}

Table I shows the results of the 30 Whistler investigations. Means and standard deviations of $H, \theta, \rho_{\mathrm{s}}, \rho_{\mathrm{B}}$, and $T_{\mathrm{B}}$ are summarized in Table II, and compared with results from our earlier study (Perla, 1977). The means from the two studies are in close enough agreement

Table I. Measurements taken at fracture line (see text for explanation)

\begin{tabular}{|c|c|c|c|c|c|c|c|c|}
\hline & & & & & & & & Crystals \\
\hline Date & Avalanche & Size & $\begin{array}{l}H \\
\mathrm{~m}\end{array}$ & $\begin{array}{c}\theta \\
\operatorname{deg}\end{array}$ & $\underset{\mathrm{kg} / \mathrm{m}^{3}}{\rho_{\mathrm{s}}}$ & $\underset{\mathrm{kg} / \mathrm{m}^{3}}{\rho_{\mathrm{B}}}$ & $\begin{array}{l}T_{\mathrm{B}} \\
{ }^{\circ} \mathrm{C}\end{array}$ & Above At Below \\
\hline I I December 1976 & Roundhouse Roll & small & 0.6 & & & & -1.5 & $I-3-5$ \\
\hline I9 January I977 & Left Hook & medium & 0.7 & & & & & $3-4-7$ \\
\hline I8 February 1977 & Whistler Roll & medium & 0.8 & & 230 & & & $2-3-5$ \\
\hline 26 February r 977 & Little Whistler W. & medium & 1.5 & 40 & 260 & & -3.0 & $2-3-5$ \\
\hline Io March 1977 & Whistler Bowl & large & 2.8 & & 260 & & & $5-3-5$ \\
\hline 24 November 1977 & Ratfink & small & 0.3 & 40 & & I 70 & -10.0 & $1-1-2$ \\
\hline 26 November I 977 & Blue Cliffs No. I & small & 0.2 & 38 & 180 & & -2.5 & $I-I-I$ \\
\hline 29 November I 977 & Mumbling Rocks & medium & 0.6 & 37 & 230 & & $-4 \cdot 5$ & $I-I-I$ \\
\hline 29 November 1977 & Downhill Start & medium & 0.6 & 44 & 220 & & -5.0 & $I-I-I$ \\
\hline 7 December 1977 & Blue Uplift & small & 0.4 & 43 & 160 & & -9.0 & $I-I-I$ \\
\hline I4 December I 977 & Glacier Wall & medium & 2.0 & 50 & & 250 & & $2-3-5$ \\
\hline I 5 December I 977 & Whistler Roll & medium & 2.2 & 38 & 230 & & -5.0 & $2-3-5$ \\
\hline 6 January I978 & Bitter End & medium & 0.6 & 33 & 160 & & -5.5 & $1-1-2$ \\
\hline 8 January I 978 & Surprise & medium & I. 4 & 31 & 200 & & -7.5 & $2-2-2$ \\
\hline 21 January 1978 & Harmony H.S. & small & 0.8 & 36 & Igo & & -4.0 & $2-6-2$ \\
\hline 22 January I 978 & Shoulder Chute & medium & 0.6 & $4^{I}$ & 180 & & & $1-1-2$ \\
\hline 1o February 1978 & West Moraine Hi & medium & I. 5 & 35 & 260 & & -1.5 & $3-4-4$ \\
\hline I I February I 978 & Glacier Wall & medium & 0.9 & 48 & 220 & & & $2-6-2$ \\
\hline 7 March 1978 & Waterfall Cornice & small & 0.2 & & & & & $\mathrm{I}-\mathrm{I}-\mathrm{I}$ \\
\hline 8 March 1978 & N. Face High & medium & 0.8 & 44 & 210 & & & $5-2-2$ \\
\hline 9 March I978 & Pacer Face & medium & 0.8 & 37 & 230 & 250 & -6.0 & $5-2-2$ \\
\hline I6 March I978 & P.K. High & small & 0.5 & 37 & 240 & & -6.0 & $1-6-2$ \\
\hline I8 March I978 & N. Face High & small & 0.4 & 42 & 190 & & -3.5 & $I-I-6$ \\
\hline 25 March 1978 & K.C. Roll & medium & I. & 38 & 220 & & -2.0 & $1-1-2$ \\
\hline I4 February I979 & Shale Slope & large & 0.5 & 37 & 240 & 290 & -4.5 & $3-3-3$ \\
\hline I5 February I979 & Boomer Bowl & large & I. I & 40 & 280 & 250 & $-3 \cdot 5$ & $2-3-3$ \\
\hline 18 February I979 & Boomer Bowl & small & 0.8 & 53 & 260 & 170 & $-5 \cdot 5$ & $2-I-2$ \\
\hline 20 February r 979 & Burnststew Traverse & large & 0.5 & 38 & 230 & & & $5-4-4$ \\
\hline 9 April 1979 & Harmony H.S. & small & 0.2 & 47 & 180 & 190 & $-3 \cdot 5$ & $\mathrm{I}-3-3$ \\
\hline I4 April I979 & Little Whistler W. & medium & o.6 & 38 & 180 & 240 & -4.0 & $3-4-4$ \\
\hline
\end{tabular}


that we feel our earlier conclusions remain valid. In particular, the following conclusions from Perla (1977) are strengthened by the Whistler results:

I. Less than $1 \%$ of all slab avalanches initiate where the slope angle is less than $25^{\circ}$.

2. Less than $5 \%$ of all slab avalanches initiate where the slope angle is less than $30^{\circ}$.

3. The average shear stress at the bed surface prior to failure is in the range of $\mathrm{IO}^{2}-\mathrm{IO}^{4}$ $\mathrm{N} / \mathrm{m}^{2}$.

4. The most prevalent bed-surface temperature is in the band $-5^{\circ} \mathrm{C}$ to $0^{\circ} \mathrm{C}$.

5 . Over $95 \%$ of all slab avalanches have a bed-surface temperature of $-10^{\circ} \mathrm{C}$ or warmer.

Note that emphasis is placed on the minimum distribution of $\theta$ values. Relevance of the mean value of $\theta$ is open to question since many slab avalanches are initiated by smaller snow masses descending from steeper terrain (cliff bands, chutes).

One factor that is not the same in the two studies is the ratio of failure shear stress at the bed surface to the bed-surface density. In the Whistler study, the mean shear stress at the bed surface $\left(\rho_{\mathrm{s}} g H \sin \theta\right)$ is almost $50 \%$ larger than the mean shear stress reported earlier because the separate factors $\rho_{\mathrm{s}}, H$, and $\theta$ are larger. What is interesting is that the Whistler mean $\rho_{\mathrm{B}}$ is lower. Although the Whistler sample size of $\rho_{\mathrm{B}}$ is too small (only 8 samples) to lead to confident conclusions, the drop in $\rho_{\mathrm{B}}$ relative to $\rho_{\mathrm{s}} g H \sin \theta$ could be explained by the fact that the earlier 72 measurements of $\rho_{B}$ summarized by Perla (1977) were obtained with relatively thick samplers $(>50 \mathrm{~mm})$ whereas the Whistler data were obtained with a thinner sampler $(20 \mathrm{~mm})$. These limited data suggest that the gleitschicht tends to be a relatively thin layer $(<50 \mathrm{~mm})$ in a significant number of cases. Another explanation is that density is a poor predictor of failure stress (Gubler, 1978), and correlations are likely to change from sample to sample.

TABLe II. Comparison OF SLAB MEASUREMENTS

\begin{tabular}{|c|c|c|c|c|c|c|}
\hline \multirow[b]{2}{*}{ Parameter } & \multicolumn{3}{|c|}{ Whistler Mountain Study } & \multicolumn{3}{|c|}{ Perla (1977) } \\
\hline & $\begin{array}{c}\text { No. of } \\
\text { cases }\end{array}$ & Mean & $\begin{array}{l}\text { Standard } \\
\text { deviation }\end{array}$ & $\begin{array}{l}\text { No. of } \\
\text { cases }\end{array}$ & Mean & $\begin{array}{l}\text { Standard } \\
\text { deviation }\end{array}$ \\
\hline Slope angle $\theta$ (deg) & 25 & 40.2 & 5.22 & I94 & 38.3 & $4 \cdot 79$ \\
\hline Slab thickness $H(\mathrm{~m})$ & 30 & 0.86 & $0.6 \mathrm{I}$ & 193 & 0.67 & 0.43 \\
\hline Slab density $\rho_{\mathrm{s}}\left(\mathrm{kg} / \mathrm{m}^{3}\right)$ & 25 & 218 & 33.6 & 121 & 206 & 77.2 \\
\hline Density at bed surface $\rho_{\mathrm{B}}\left(\mathrm{kg} / \mathrm{m}^{3}\right)$ & 8 & 226 & $44 \cdot 1$ & 72 & 231 & 75.9 \\
\hline Temperature at bed surface $T_{\mathrm{B}}\left({ }^{\circ} \mathrm{C}\right)$ & 21 & -4.64 & 2.24 & III & -4.58 & 3.08 \\
\hline
\end{tabular}

\section{METHODS: PHOTOMICROGRAPHY}

Figure I shows our arrangement for collecting a snow sample from the neighbourhood of the intersection of the crown and bed surfaces. A partitioned sample can was carefully inserted at the intersection so that the partitions aligned with the crown and bed surfaces. The can, which now contained the sample, was delicately cut out from the snow, capped, and inserted into a larger cylindrical can. Snow was packed inside the larger cylinder and around the sample can in order to prevent melting and minimize shock disturbance during transport, which was by backpack on skis to a refrigerated laboratory at the top of the Whistler ski area.

In the laboratory, the sample can was tapped sharply in order to induce a fracture along the bed-surface extension. If there was no fracture, then the axis of the bed-surface extension was visually estimated with the aid of the reference partition (we were able to obtain a fracture in about ro of the 30 cases). After locating the axis of the bed-surface extension as closely as possible, a tiny V-shaped chisel was used to extract carefully a sample of about io to Ioo snow grains from a band approximately $10 \mathrm{~mm}$ thick immediately above the axis. The grains were placed in a petri dish, and the dish was tapped in order to disaggregate the grains 
into separate crystals as much as possible. The grains were then photographed using transmitted polarized light with the nicols in an uncrossed position. The polarized light was used to accentuate crystal boundaries.

We called the grains extracted from just above the axis of the bed surface extension the "at" grains. For comparison, a second set of grains, which we called the "below" grains, was extracted from an axis below the bed surface extension; and similarly, a third set of grains was extracted from an "above" axis. Our initial plan was to extract the "above" and "below" grains from respective axes $50 \mathrm{~mm}$ above and below the bed-surface extension. However, as the study progressed it became clear that the more interesting "above" and "below" layers did not necessarily coincide with the $50 \mathrm{~mm}$ spacing. For example, in ro of our 30 cases, visual inspection of the sample can revealed crust layers along axes usually spaced closer to the "at" layer than $50 \mathrm{~mm}$. Crusts and other anomalies that appeared to form natural boundaries of the gleitschicht were sampled in preference to the $50 \mathrm{~mm}$ layers.

\section{RESULTS: PHOTOMICROGRAPHY}

The far right column in Table $I$ is a summary of the types of crystals observed in the photomicrographs of the above, at, and below layers. The type of crystal is coded by a number $(\mathrm{I}-7)$ based on the international system of snow classification (UNESCO, 1970) as follows:

I. New and initially metamorphosed crystals. Original crystal shapes (plates, columns, dendrites) as formed in atmospheric clouds can be recognized despite initial sublimation, wind fragmentation, or riming. Plate-like forms appear colourless when illuminated with transmitted, polarized light. Prisms show some colour.

2. Rounded crystals. The majority of the crystals appear to have rounded surfaces, although flat faces are visible at crystal bonds. Original atmospheric forms are no longer obvious. Polarized light may produce some colours depending on crystal thickness. The projected crystal area is less than one square millimetre, and often closer to $10^{-1}$ or $\mathrm{IO}^{-2} \mathrm{~mm}^{2}$.

3. Faceted crystals. The majority of the crystals appear to have flat surfaces and angular corners. Polarized light brings out a variety of colours. The projected area of these crystals may exceed several square millimetres.

4. Stepped crystals. These are enlarged, faceted crystals which, when examined under transmitted light, appear to consist of many steps or layers. The steps sometimes spiral around to form a cup. Polarized light reveals brilliant colours.

5. Crusts. This category is determined primarily by the relative strength of the layer and its resistance to disaggregation. Photomicrographs reveal colourful conglomerates of tightly packed crystals.

6. Surface hoar. The Whistler variety of surface hoar typically includes large, fan-shaped crystals. Projected area often exceeds ro $\mathrm{mm}^{2}$. Although step-like features are obvious, these crystals are easily distinguished from Category 4 by their relative lack of colour under polarized light, at least in their early stages of metamorphism.

The code 7 was used in one case (19 January 1977) where the bed surface was immediately above the ground, and it was not possible to sample a below layer.

Many of the photomicrographs were disappointing in the sense that the "at" crystals did not appear very different from the "above" and "below" crystals. For half the investigations shown in the far right column of Table I the "at" crystals were classified the same as either the "above" or "below" crystals. Three notable exceptions are shown in Figure 2. The "at" crystals from the Boomer Bowl investigation of 18 February 1979 stand out as relatively unmetamorphosed stellar fragments (Category I) sandwiched between the rounded crystals (Category 2) shown in the "above" and "below" photomicrographs. The "at" crystals from 
the PK-high investigation of 16 March 1979 stand out as surface hoar (Category 6), whereas the "above" crystals are initially metamorphosed stellar fragments (Category I), and the "below" crystals are classified as rounded (Category 2), although there is some evidence of stellar shapes. The Whistler Bowl photomicrographs, Io March I977, show faceted crystals (Category 3) sandwiched between large conglomerates taken from ice crusts (Category 5).
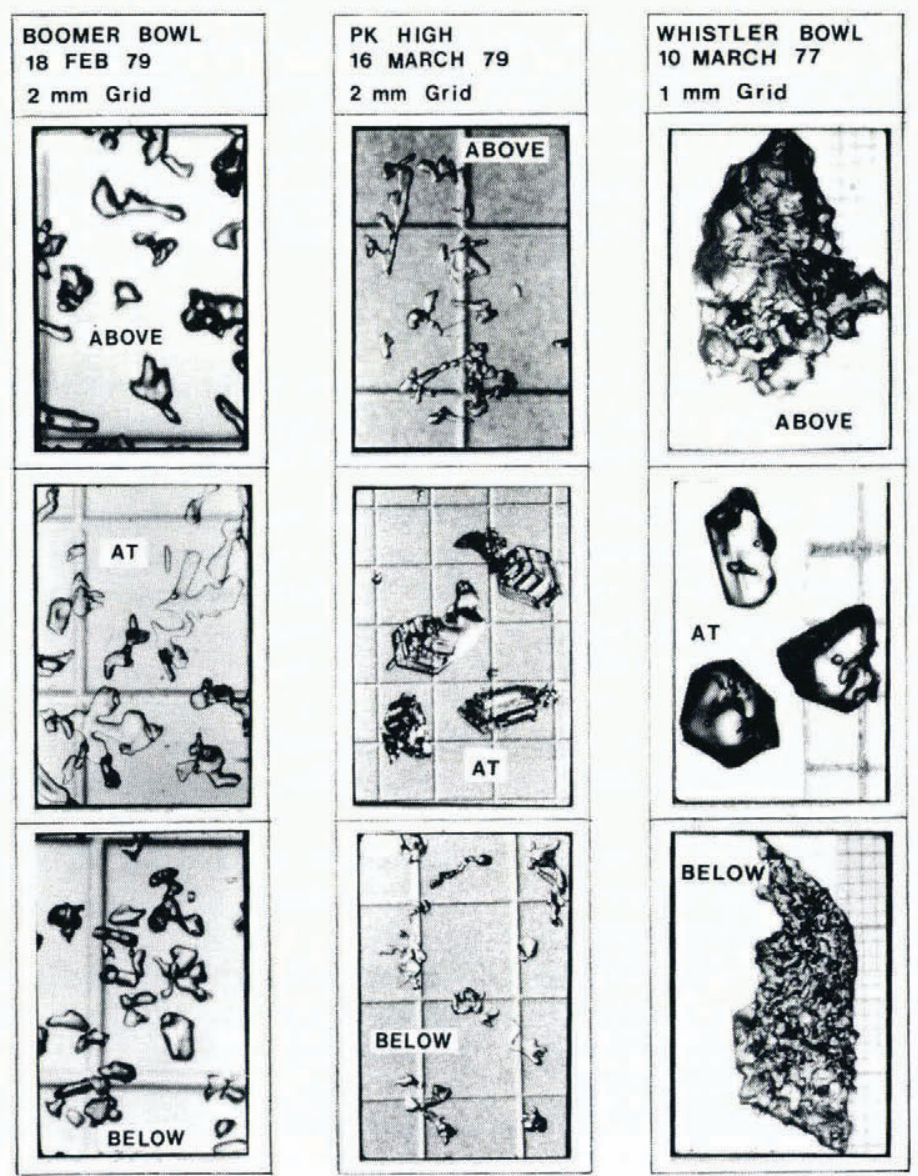

Fig. 2. Examples of photomicrographs.

\section{Discussion}

We feel the recurring statistics of bed-surface slope angles have practical significance, especially for back-country skiers who are well advised to avoid slopes steeper than $25^{\circ}$ if there is any doubt about snow stability. We have again found that bed-surface temperatures are essentially in the band $0^{\circ} \mathrm{C}$ to $-10^{\circ} \mathrm{C}$. Since it is exceedingly rare for the bed surface of a thick slab $(H>\mathrm{I} \mathrm{m})$ to have a temperature colder than $-5^{\circ} \mathrm{C}$, we feel laboratory tests of shear strength and related properties should emphasize warmer temperatures than the somewhat arbitrary $-10^{\circ} \mathrm{C}$ that is conventional in many snow studies. Similarly, the densities of prime interest are probably in the band $200 \mathrm{~kg} / \mathrm{m}^{3}$ to $250 \mathrm{~kg} / \mathrm{m}^{3}$, the lower limit corresponding to gleitschicht densities, and the upper limit to slab densities. 
Improvement of our photomicrography method is certainly needed. A three-layer model of the gleitschicht ("above"-"at"-"below") turned out to be a naive oversimplification of Nature. In our future work we will attempt to photograph the intact texture of the gleitschicht using plane sections.

\section{AGKnowledgement}

This study was only possible with the help of Garibaldi Lifts Ltd, Whistler, B.C. Correspondence with Professor E. R. LaChapelle, University of Washington, influenced many of our ideas.

\section{REFERENCES}

Gubler, H. 1978. Determination of the mean number of bonds per snow grain and of the dependence of the tensile strength of snow on stereological parameters. Fournal of Glaciology, Vol. 20, No. 83, p. 329-4I.

Perla, R. I. 1977. Slab avalanche measurements. Canadian Geotechnical Journal, Vol. 14, No. 2, p. $206-13$.

Stethem, C., and Hetherington, J. 1978. Whistler Mountain avalanche control programme. Canada. National Research Council. Technical Memorandum No. 120, p. 24-29.

UNESCO. 1970. Seasonal snow cover: a guide for measurement compilation and assemblage of data. A contribution to the International Hydrological Decade. Paris, United Nations Educational, Scientific and Cultural Organization. 